\title{
Variability Studies in Fruits and Seed Characters of Aquilaria malaccensis
}

\author{
N. $\operatorname{Ravi}^{1 *}$, R. Hegde ${ }^{2}$, Supriya K. Salimath², Aparna Rajan ${ }^{1}$, \\ S. Shilpa Shenoy ${ }^{1}$ and S. Bordoloi ${ }^{3}$ \\ ${ }^{1}$ Institute of Wood Science and Technology, (ICFRE), Malleshwaram, \\ Bangalore, Karnataka, India \\ ${ }^{2}$ College of Forestry, Ponnampet, UAHS Shivamogga, Karnataka, India \\ ${ }^{3}$ Rain Forest Research Institute, (ICFRE), Jorhat, Assam, India \\ *Corresponding author
}

\section{A B S T R A C T}

\begin{tabular}{|l|}
\hline Key w o r d s \\
Aquilaria \\
malaccensis, Broad \\
sense heritability, \\
Phenotypic, \\
Genotypic \\
correlations
\end{tabular}

\section{Introduction}

Aquilaria malaccensis Lam. is one of the 15 tree species in the Indo-malaesian genus Aquilaria belongs to family Thymelaeaceae (Ng et al., 1997). The tree grows in natural forests at an altitude of a few meters above sea level to about $1000 \mathrm{~m}$, and it grows best around $500 \mathrm{~m}$ in locations with average daily temperatures of 20 to $22^{\circ} \mathrm{C}$ (Keller and Sidiyasa, 1994; Wiriadinata., 1995). The tree is traded internationally for the agarwood, which produced in its trunk to protect the tree when it is wounded and infected by fungus (Liu Y. et al., 2013; Mohamed et al., 2014) and has been used for incense as well as a traditional sedative, an analgesic and digestive medicine (Yagura et al., 2005). In India, A. malaccensis grows mostly in the foothills of the North-eastern region (Assam, Meghalaya, Nagaland, Mizoram, Manipur, Arunachal Pradesh and Tripura) and West Bengal up to an altitude of 1000 m. In Assam and Meghalaya, it occurs sporadically in the 
district of Sibsagar, Sadiya, Nowgong, Darrang, Goalpara, Garo Hills and Cachar (Atal and Kapoor, 1982). Aquilaria sp. has adapted to live in various habitats, including those that are rocky, sandy or calcareous, well-drained slopes and ridges and land near swamps (Chakrabarty et al., 1994; Sumadiwangsa, 1997). Over exploitation of the species due to international demand, made the species more threatened and entered into CITES Appendix-II (CITES, 1994).

The number of trees in the natural habitats has been reduced and the species is widely grown in the home gardens of North East India to meet the demand. Considering the economic value of the agarwood, the species is introduced in the Western Ghats regions of Karnataka and Kerala and in some places of Tamil Nadu. The formation of agarwood in the tree depends on natural infection and only few trees produces agar wood. There is no successful artificial inoculation method available for the production of agarwood in the agar tree. Unfortunately, before understanding the role of genetics and environment in formation of agar wood, the trees in plantations, natural habitat and home gardens were vanished for the demand of agarwood.

The population in the natural habitat is disappearing and further, plantations are raised with unknown seed sources, leading to inbreeding. If continued at the same level as now low levels of genetic diversity within species can lead to inbreeding depression which affects growth, survival and adaptation (Kjaer, 1997) leading to genetic loss. Genetic variation within and between species is important to the long-term natural adaptation of species (Falk and Holsinger, 1991). Hence, a attempt to explore the existing variations in the species and conserving those germplasm is done in the present study.

\section{Materials and Methods}

The study was conducted in Institute of wood science and technology, Bangalore. Based on the existing literature and interaction with the local people different natural populations were identified and located on the geopolitical map of the region. Each located points were visited and reconnaissance survey was carried out in the region and totally 44 phenotypically superior trees (Candidate trees) were selected in North East India comprising Assam, Arunachal Pradesh, Meghalaya, Nagaland and Tripura. Along with these 44 trees in the natural populations two introduced populations, one each from Karnataka and Tamil Nadu were also considered for the study (Table 1). Matured fruits were collected from selected candidate trees from May to September, 2019. The collected fruits were brought within 3-4 days to the laboratory at Institute of Wood Science and Technology, Bangalore. A total of 20 fruits were taken randomly from each tree seed lot with identity and subjected to morphometric measurements of fruits and seeds. Fruits were measured for its weight, width and length. The fruits were predominantly double seeded and some of them were single seeded. Seeds were separated from the fruits and the seed weight, length and width of the seeds were recorded. All measurements were made with digital Vernier Caliper $(0.01 \mathrm{~mm}$ precision $)$ and digital electronic balance $(0.001 \mathrm{~g}$ precision). The average of weight, length and width of seeds were taken for statistical analysis where the fruits are two seeded. In all, data from 920 fruits and seeds were considered for the study.

\section{Data analysis}

Statistical analysis of the data was carried out by using the Crop Stat for Windows Version 7.2.2007.3 software by grouping the entire population under six regions. The phenotypic and genotypic correlation and broad sense 
heritability for the fruit and seed traits were determined using the Plant Breeding Tools (PBTools), Version: 1.3 software (International Rice Research Institute http://bbi.irri.org).

\section{Results and Discussion}

\section{Variation in the fruit and seed traits among the populations of different regions}

Important fruit and seed traits of different populations are the indicators of similarity or variability between the populations and data pertaining to fruit and seed traits of different populations are presented in Table 2 . Existences of significant variation in the different populations with respect to fruit and seed traits were evident in the present study. Among the different populations, introduced population had significantly higher values for all the fruit traits. Among the natural populations, population from Assam and Meghalaya had on par values for fruit weight (1.86g each) and were significantly higher over populations from Arunachal Pradesh (1.76 g), Nagaland (1.74 g) and Tripura (1.71 g). Fruit length of different natural populations were found to be on par except Tripura population $(28.09 \mathrm{~mm})$ which was significantly lower over all the populations. Similar trend was observed in the fruit width of different natural populations wherein Tripura population had significantly lower value $(28.09 \mathrm{~mm})$ compared to other populations. Fruit thickness of different natural populations varied significantly and among them, Meghalaya (12.29 $\mathrm{mm})$ had significantly higher value over Nagaland (11.75 mm), Arunachal Pradesh (11.42 mm), Assam $(11.18 \mathrm{~mm})$ and the least value was recorded for Tripura (10.99) which was significantly lower to all other populations,

Existence of significant variation in seed traits of different populations was evident in the present study (Table 2). Seed weight of introduced population $(0.20 \mathrm{~g})$ had significantly higher value and was on par with Assam population $(0.18 \mathrm{~g})$. On the other hand, seed length of Arunachal Pradesh source $(14.77 \mathrm{~mm})$ had significantly higher values over Meghalaya (14.30 mm) Nagaland $(13.48 \mathrm{~mm})$ and Tripura sources $(13.39 \mathrm{~mm})$ and was on par with Assam $(14.62 \mathrm{~mm})$ and introduced populations $(14.50 \mathrm{~mm})$. Seed width of introduced populations was found to be significantly higher $(4.54 \mathrm{~mm})$ over all the natural populations. Interestingly, seed width among the different natural populations did differ significantly. The values on the number of seeds per fruit were also varied significantly and Nagaland population (1.89) had significantly higher values over other populations except introduced population (1.87). Number of seeds per fruit in other populations did vary considerably and the least number of seeds per fruit was observed in Meghalaya (1.58) and Arunachal Pradesh populations (1.55).

\section{Variation in fruit and seed traits of candidate trees of different populations}

Data on fruit and seed traits of different candidate trees of different populations are presented in Table 3 and the perusal of the data on fruit characters of candidate trees revealed the significant difference in fruit characters of different candidate trees. Among the different populations studied, maximum fruit weight of $2.16 \mathrm{~g}$ was recorded in tree number 19 and tree numbers 1,8 and 21 recorded the lowest fruit weight $(1.68 \mathrm{~g})$. Tree number 46 from introduced population had the highest value of fruit length which was $31.89 \mathrm{~mm}$ whereas the lowest value of fruit length $(26.24 \mathrm{~mm})$ was recorded from the tree number 45 which was also from introduced population from different locality. Fruit width of different candidate trees varied significantly and values were in the range of 
$9.86 \mathrm{~mm}$ (Tree42) to $12.86 \mathrm{~mm}$ (Tree 33). Fruit thickness of different trees differed significantly with values ranging from 13.34 $\mathrm{mm}$ (Tree 42) to $18.08 \mathrm{~mm}$ (Tree 39).

Close perusal of the data on seed traits of candidate trees from different populations revealed the existence of significant variation in the seed traits of candidate trees from different populations except seed weight. The seed weight of different trees varied from $0.13 \mathrm{~g}$ to $0.19 \mathrm{~g}$. Seed length of different candidate trees varied significantly with values ranging from $12.73 \mathrm{~mm}$ (Tree 17) to $15.37 \mathrm{~mm}$ (Tree 7). Seed width of different candidate trees varied from $3.37 \mathrm{~mm}$ (Tree 15) to $4.56 \mathrm{~mm}$ (Tree 6) and the values differed significantly. Number of seeds per fruit did vary considerably where the values varied from 1.42 to 2.16 (Tree 24).

\section{Broad sense heritability}

The analysis on broad sense heritability of the fruit and seed traits indicated higher values (Table 4). In case of fruit traits the broad sense heritability values varied from 0.82 to 0.90 and values for seed traits were ranging from 0.71 to 0.96 . Among the different fruit characters, the fruit thickness had relatively higher value (0.90) followed by fruit width (0.89) fruit length and fruit weight (0.82). Close perusal of the data presented on the broad sense heritability of different seed traits revealed that the values were ranging from 0.71 (seed weight, number of seeds per fruit) to 0.96 (Seed width).

Table.1 Geographical details of regions and candidate trees for the study

\begin{tabular}{|c|c|c|c|c|c|}
\hline Sl.No. & Region & $\begin{array}{l}\text { No. of } \\
\text { Trees }\end{array}$ & $\begin{array}{l}\text { Latitudinal } \\
\text { range }\end{array}$ & $\begin{array}{l}\text { Longitudinal } \\
\text { range }\end{array}$ & $\begin{array}{l}\text { Altitudinal } \\
\text { range(MSL) }\end{array}$ \\
\hline 1 & Assam & 22 & $\begin{array}{c}\text { N } 26^{0} 32^{\prime} 54.7^{\prime \prime} \\
\text { To } \\
\text { N 27 } 5957.0^{\prime \prime}\end{array}$ & $\begin{array}{c}\text { E } 94^{0} 00^{\prime} 03.0^{\prime \prime} \\
\text { To } \\
\text { E } 95^{\circ} 45^{\prime} 28.0^{\prime \prime}\end{array}$ & $95-163$ \\
\hline 2 & Arunachal Pradesh & 7 & $\begin{array}{c}\text { N } 27^{0} 06^{0} 54.3^{\prime \prime} \\
\text { To } \\
\text { N } 28^{0} 04^{\prime} 04.4^{\prime \prime}\end{array}$ & $\begin{array}{c}\text { E } 93^{0} 48 \text { '20.4" } \\
\text { To } \\
\text { E } 95^{\circ} 28^{\prime} 46.7^{\prime \prime}\end{array}$ & $137-163$ \\
\hline 3 & Meghalaya & 3 & $\begin{array}{c}\text { N } 25^{0} 32^{\prime} 39.2^{\prime \prime} \\
\text { To } \\
\text { N 25 } 55^{\circ} 59.0^{\prime \prime}\end{array}$ & $\begin{array}{c}\text { E } 90^{0} 1354.6^{\prime \prime} \\
\text { To } \\
\text { E } 90^{0} 3975.0^{\prime \prime}\end{array}$ & $68-137$ \\
\hline 4 & Tripura & 8 & $\begin{array}{c}\mathrm{N} 23^{0} 33^{\prime} 45.2^{\prime \prime} \\
\text { To } \\
\text { N } 23^{0} 53^{\prime} 13.7^{\prime \prime}\end{array}$ & $\begin{array}{c}\text { E } 91^{0} 17^{\prime} 03.2^{\prime \prime} \\
\text { To } \\
\text { E } 91^{0} 25^{\prime} 50.4^{\prime \prime}\end{array}$ & $31-39$ \\
\hline 5 & Nagaland & 4 & $\begin{array}{c}\text { N } 26^{0} 17^{\prime} 20.4^{\prime \prime} \\
\text { To } \\
\text { N 26 }\end{array}$ & $\begin{array}{c}\text { E 94023'57.1" } \\
\text { To } \\
\text { E 94023 } 59.2^{\prime \prime}\end{array}$ & $1075-1088$ \\
\hline \multirow[t]{2}{*}{6} & $\begin{array}{l}\text { Introduced sources } \\
\text { (i) Ponnampet, Karnataka }\end{array}$ & 1 & $\mathrm{~N} 12^{\circ} 08^{\prime} 35.2^{\prime \prime}$ & E $75^{\circ} 56^{\prime} 19.3^{\prime \prime}$ & 916 \\
\hline & (ii) Karumandruai, Tamil Nadu & 1 & N 11 ${ }^{\circ} 48^{\prime} 51.4^{\prime \prime}$ & E $076^{\circ} 37^{\prime} 21.6^{\prime \prime}$ & 766 \\
\hline
\end{tabular}


Table. 2 Variations in fruit and seed traits among the populations of different regions

\begin{tabular}{|l|l|l|l|l|l|l|l|l|l|}
\hline SI No & Populations & $\begin{array}{c}\text { Fruit } \\
\text { Weight }\end{array}$ & $\begin{array}{l}\text { Fruit } \\
\text { length } \\
\text { (g) }\end{array}$ & $\begin{array}{c}\text { Fruit } \\
\text { width }\end{array}$ & $\begin{array}{c}\text { Fruit } \\
\text { (mm) }\end{array}$ & $\begin{array}{c}\text { Seed } \\
\text { Thickness } \\
(\mathbf{m m})\end{array}$ & $\begin{array}{c}\text { Seed } \\
\text { weight } \\
\text { (g) }\end{array}$ & $\begin{array}{c}\text { Seed } \\
\text { Length } \\
\text { Width }\end{array}$ & $\begin{array}{l}\text { Seed /fruit (\#) } \\
\text { (mm) }\end{array}$ \\
\hline $\mathbf{1}$ & Assam & 1.86 & 29.16 & 16.03 & 11.18 & 0.18 & 14.62 & 4.27 & $1.78(1.33)^{*}$ \\
\hline $\mathbf{2}$ & $\begin{array}{l}\text { Arunachal } \\
\text { Pradesh }\end{array}$ & 1.76 & 29.08 & 15.70 & 11.42 & 0.14 & 14.77 & 3.90 & $1.58(1.26)$ \\
\hline $\mathbf{3}$ & Meghalaya & 1.86 & 29.33 & 15.61 & 12.29 & 0.13 & 14.30 & 3.73 & $1.55(1.25)$ \\
\hline $\mathbf{4}$ & Tripura & 1.71 & 28.09 & 14.98 & 10.99 & 0.14 & 13.39 & 3.57 & $1.67(1.29)$ \\
\hline $\mathbf{5}$ & Nagaland & 1.74 & 28.91 & 15.61 & 11.75 & 0.17 & 13.48 & 3.42 & $1.89(1.38)$ \\
\hline $\mathbf{6}$ & Introduced & 2.23 & 31.72 & 16.83 & 12.78 & 0.20 & 14.50 & 4.54 & $1.87(1.37)$ \\
\hline & source & & & & & & & & \\
\hline
\end{tabular}

*Values in parenthesis are square root transformed values

Table.3 Mean fruits and seeds traits of individual candidate trees

\begin{tabular}{|l|l|l|l|l|l|l|l|l|}
\hline $\begin{array}{l}\text { Candidate } \\
\text { Tree No. }\end{array}$ & $\begin{array}{c}\text { Fruit } \\
\text { weight } \\
\mathbf{( g )}\end{array}$ & $\begin{array}{c}\text { Fruit } \\
\text { length } \\
\mathbf{( m m}\end{array}$ & $\begin{array}{c}\text { Fruit } \\
\text { width } \\
\mathbf{( m m}\end{array}$ & $\begin{array}{c}\text { Fruit } \\
\text { thickness } \\
\mathbf{( m m}\end{array}$ & $\begin{array}{c}\text { Seed } \\
\text { weight } \\
\mathbf{( g )}\end{array}$ & $\begin{array}{c}\text { Seed } \\
\text { Length } \\
\mathbf{( m m})\end{array}$ & $\begin{array}{c}\text { Seed } \\
\text { Width } \\
\text { (mm) }\end{array}$ & $\begin{array}{c}\text { Seed } \\
\text { /fruit } \\
\text { (\#) }\end{array}$ \\
\hline $\mathbf{1}$ & 1.68 & 28.74 & 10.93 & 15.14 & 0.19 & 15.19 & 4.32 & $\begin{array}{l}1.82 \\
(1.35)^{*}\end{array}$ \\
\hline $\mathbf{2}$ & 1.78 & 28.90 & 10.83 & 15.54 & 0.18 & 13.84 & 4.04 & $1.88(1.37)$ \\
\hline $\mathbf{3}$ & 1.97 & 29.34 & 11.51 & 15.92 & 0.16 & 14.57 & 4.28 & $1.72(1.31)$ \\
\hline $\mathbf{4}$ & 1.96 & 30.29 & 11.92 & 15.91 & 0.15 & 14.54 & 4.28 & $1.56(1.25)$ \\
\hline $\mathbf{5}$ & 1.79 & 30.15 & 11.18 & 15.53 & 0.16 & 13.65 & 4.11 & $1.72(1.31)$ \\
\hline $\mathbf{6}$ & 1.87 & 30.60 & 11.22 & 16.21 & 0.16 & 14.45 & 4.56 & $1.82(1.35)$ \\
\hline $\mathbf{7}$ & 1.77 & 30.65 & 10.86 & 15.52 & 0.16 & 15.37 & 4.13 & $1.72(1.31)$ \\
\hline $\mathbf{8}$ & 1.68 & 27.58 & 10.71 & 15.47 & 0.14 & 14.20 & 3.89 & $1.61(1.27)$ \\
\hline $\mathbf{9}$ & 1.82 & 29.21 & 11.43 & 15.60 & 0.15 & 15.02 & 4.08 & $1.72(1.31)$ \\
\hline $\mathbf{1 0}$ & 1.83 & 29.20 & 11.84 & 15.56 & 0.17 & 14.89 & 4.12 & $1.88(1.37)$ \\
\hline $\mathbf{1 1}$ & 1.87 & 31.22 & 11.74 & 15.68 & 0.17 & 13.83 & 4.08 & $1.82(1.35)$ \\
\hline $\mathbf{1 2}$ & 2.06 & 28.85 & 12.17 & 16.67 & 0.15 & 14.24 & 3.99 & $1.66(1.29)$ \\
\hline $\mathbf{1 3}$ & 1.73 & 28.46 & 10.92 & 15.06 & 0.19 & 14.02 & 4.05 & $1.72(1.31)$ \\
\hline $\mathbf{1 4}$ & 1.80 & 28.98 & 11.15 & 15.97 & 0.15 & 14.24 & 3.71 & $1.77(1.33)$ \\
\hline $\mathbf{1 5}$ & 1.76 & 28.36 & 12.44 & 16.35 & 0.18 & 14.52 & 3.37 & $1.82(1.35)$ \\
\hline $\mathbf{1 6}$ & 1.76 & 27.61 & 10.85 & 15.58 & 0.16 & 14.35 & 3.73 & $1.82(1.35)$ \\
\hline $\mathbf{1 7}$ & 1.92 & 27.74 & 12.02 & 16.63 & 0.13 & 12.73 & 3.70 & $1.56(1.25)$ \\
\hline $\mathbf{1 8}$ & 1.72 & 29.70 & 10.89 & 15.27 & 0.14 & 14.69 & 4.34 & $1.77(1.33)$ \\
\hline $\mathbf{1 9}$ & 2.16 & 28.88 & 12.48 & 16.77 & 0.19 & 14.43 & 3.70 & $1.93(1.39)$ \\
\hline $\mathbf{2 0}$ & 1.79 & 29.00 & 11.16 & 16.28 & 0.19 & 14.22 & 4.01 & $1.77(1.33)$ \\
\hline $\mathbf{2 1}$ & 1.68 & 27.55 & 11.15 & 14.79 & 0.14 & 13.46 & 3.81 & $1.51(1.23)$ \\
\hline & & & & & & & & \\
\hline
\end{tabular}




\begin{tabular}{|c|c|c|c|c|c|c|c|c|}
\hline 22 & 1.77 & 28.40 & 10.83 & 15.47 & 0.15 & 14.20 & 3.62 & $1.51(1.23)$ \\
\hline 23 & 1.70 & 29.63 & 10.72 & 15.22 & 0.17 & 14.34 & 4.38 & $1.77(1.33)$ \\
\hline 24 & 1.89 & 30.12 & 10.81 & 15.95 & 0.19 & 14.14 & 3.97 & $2.16(1.47)$ \\
\hline 25 & 1.87 & 28.99 & 11.09 & 16.28 & 0.16 & 14.18 & 3.73 & $1.77(1.33)$ \\
\hline 26 & 1.69 & 27.85 & 11.02 & 15.05 & 0.16 & 14.22 & 3.88 & $1.54(1.24)$ \\
\hline 27 & 1.78 & 28.87 & 11.60 & 15.22 & 0.15 & 14.28 & 4.16 & $1.59(1.26)$ \\
\hline 28 & 1.94 & 28.70 & 12.15 & 16.26 & 0.15 & 13.79 & 3.83 & $1.59(1.26)$ \\
\hline 29 & 1.92 & 29.28 & 12.22 & 16.41 & 0.16 & 15.17 & 4.03 & $1.72(1.31)$ \\
\hline 30 & 1.86 & 28.69 & 11.04 & 16.12 & 0.16 & 14.82 & 4.13 & $1.61(1.27)$ \\
\hline 31 & 1.83 & 29.31 & 11.48 & 15.58 & 0.17 & 14.25 & 4.11 & $1.77(1.33)$ \\
\hline 32 & 1.79 & 29.19 & 11.60 & 15.60 & 0.16 & 13.84 & 3.75 & $1.77(1.33)$ \\
\hline 33 & 1.89 & 30.36 & 12.86 & 16.14 & 0.17 & 14.62 & 4.13 & $1.82(1.35)$ \\
\hline 34 & 1.73 & 28.73 & 10.97 & 14.73 & 0.14 & 14.56 & 3.91 & $1.56(1.25)$ \\
\hline 35 & 1.83 & 29.09 & 10.24 & 15.00 & 0.19 & 14.60 & 3.77 & $2.04(1.43)$ \\
\hline 36 & 1.88 & 29.32 & 10.16 & 15.04 & 0.17 & 14.59 & 4.07 & $1.82(1.35)$ \\
\hline 37 & 1.89 & 29.68 & 11.57 & 15.33 & 0.16 & 14.51 & 4.17 & $1.66(1.29)$ \\
\hline 38 & 1.79 & 28.59 & 11.02 & 16.35 & 0.18 & 14.42 & 4.10 & $1.93(1.39)$ \\
\hline 39 & 1.83 & 28.16 & 12.50 & 18.08 & 0.14 & 14.20 & 4.13 & $1.42(1.19)$ \\
\hline 40 & 1.77 & 28.59 & 11.67 & 15.50 & 0.15 & 12.90 & 3.69 & $1.61(1.27)$ \\
\hline 41 & 1.84 & 29.77 & 11.26 & 16.73 & 0.16 & 14.37 & 3.80 & $1.66(1.29)$ \\
\hline 42 & 1.82 & 29.26 & 9.86 & 13.34 & 0.17 & 14.24 & 3.96 & $1.82(1.35)$ \\
\hline 43 & 1.92 & 28.53 & 11.96 & 16.55 & 0.17 & 14.29 & 4.17 & $1.82(1.35)$ \\
\hline 44 & 1.72 & 28.70 & 12.42 & 16.45 & 0.15 & 14.31 & 4.06 & $1.61(1.27)$ \\
\hline 45 & 1.74 & 26.24 & 11.96 & 14.69 & 0.16 & 13.85 & 3.49 & $1.66(1.29)$ \\
\hline 46 & 1.92 & 31.89 & 10.78 & 16.85 & 0.16 & 14.76 & 4.50 & $1.77(1.33)$ \\
\hline CD (0.05) & 0.72 & 0.18 & 1.46 & 0.82 & NS & 0.61 & 0.26 & 0.10 \\
\hline SEM & 0.26 & 0.06 & 0.53 & 0.30 & 0.015 & 0.22 & 0.09 & 0.04 \\
\hline
\end{tabular}

*Values in parenthesis are square root transformed values

Table.4 Broad Sense Heritability of fruit and seed traits of A. malaccensis

\begin{tabular}{|l|l|c|}
\hline SI.No. & Traits & $\begin{array}{c}\text { Broad Sense Heritability } \\
\left(\mathbf{H}^{\mathbf{2}} \mathbf{)}\right.\end{array}$ \\
\hline $\mathbf{1}$ & Fruit weight & 0.82 \\
\hline $\mathbf{2}$ & Fruit length & 0.82 \\
\hline $\mathbf{3}$ & Fruit width & 0.89 \\
\hline $\mathbf{4}$ & Fruit thickness & 0.90 \\
\hline $\mathbf{5}$ & Seeds per fruit & 0.71 \\
\hline $\mathbf{6}$ & Seed weight & 0.71 \\
\hline $\mathbf{7}$ & Seed Width & 0.96 \\
\hline $\mathbf{8}$ & Seed Length & 0.91 \\
\hline
\end{tabular}


Table.5 Phenotypic Correlations between fruit and seed traits of A. malaccensis

\begin{tabular}{|l|l|l|l|l|l|l|l|l|}
\hline & $\begin{array}{l}\text { Fruit } \\
\text { weight }\end{array}$ & $\begin{array}{l}\text { Fruit } \\
\text { length }\end{array}$ & $\begin{array}{l}\text { Fruit } \\
\text { width }\end{array}$ & $\begin{array}{l}\text { Fruit } \\
\text { thickness }\end{array}$ & $\begin{array}{l}\text { Seed } \\
\text { weight }\end{array}$ & $\begin{array}{l}\text { Seed } \\
\text { Width }\end{array}$ & $\begin{array}{l}\text { Seed } \\
\text { Length }\end{array}$ & $\begin{array}{l}\text { Seed per } \\
\text { fruit }\end{array}$ \\
\hline Fruit weight & 1.00 & & & & & & & \\
\hline Fruit length & 0.58 & 1.00 & & & & & & \\
\hline Fruit width & 0.61 & 0.35 & 1.00 & & & & & \\
\hline Fruit thickness & 0.47 & 0.17 & 0.55 & 1.00 & & & & \\
\hline Seed weight & 0.45 & 0.34 & 0.31 & -0.08 & 1.00 & & & \\
\hline Seed Width & 0.48 & 0.59 & 0.39 & -0.07 & 0.53 & 1.00 & & \\
\hline Seed Length & 0.30 & 0.43 & 0.29 & -0.03 & 0.37 & 0.65 & 1.00 & \\
\hline Seed per fruit & 0.29 & 0.34 & 0.08 & -0.16 & 0.76 & 0.20 & 0.11 & 1.00 \\
\hline
\end{tabular}

Table.6 Genotypic Correlation between fruit and seed traits of A. malaccensis

\begin{tabular}{|l|c|c|c|c|c|c|c|c|}
\hline & $\begin{array}{c}\text { Fruit } \\
\text { weight }\end{array}$ & $\begin{array}{c}\text { Fruit } \\
\text { length }\end{array}$ & $\begin{array}{c}\text { Fruit } \\
\text { width }\end{array}$ & $\begin{array}{c}\text { Fruit } \\
\text { thickness }\end{array}$ & $\begin{array}{c}\text { Seed } \\
\text { weight }\end{array}$ & $\begin{array}{c}\text { Seed } \\
\text { Width }\end{array}$ & $\begin{array}{c}\text { Seed } \\
\text { Length }\end{array}$ & $\begin{array}{c}\text { Seed per } \\
\text { fruit }\end{array}$ \\
\hline Fruit weight & 1.00 & & & & & & & \\
\hline Fruit length & 0.64 & 1.00 & & & & & & \\
\hline Fruit width & 0.63 & 0.36 & 1.00 & & & & & \\
\hline Fruit thickness & 0.48 & 0.18 & 0.56 & 1.00 & & & & \\
\hline Seed weight & 0.54 & 0.42 & 0.37 & -0.10 & 1.00 & & & \\
\hline Seed Width & 0.53 & 0.67 & 0.41 & -0.08 & 0.64 & 1.00 & & \\
\hline Seed Length & 0.34 & 0.48 & 0.31 & -0.04 & 0.45 & 0.69 & 1.00 & \\
\hline Seed per fruit & 0.34 & 0.42 & 0.08 & -0.21 & 0.86 & 0.25 & 0.16 & 1.00 \\
\hline
\end{tabular}

Phenotypic and genetic correlation between traits

The data on phenotypic correlations for fruit and seed characters of A.malaccensis are depicted in Table 5. Perusal of the data revealed high significant positive correlation between number of seeds and total seed weight (0.76) seed width and seed length (0.65). The data also revealed that the fruit and seed traits have a positive phenotypic correlation except for fruit thickness which exhibited a negative correlation with seed traits of A. malaccensis. The statistical analysis for genetic correlation between fruit and seed characters revealed that there exists a positive correlation between fruit and seed characters except for fruit thickness which recorded a weak negative correlation with the seed characters (Table 6).
Variation in fruit and seed traits of different populations

The variability between trees occur due to three causes viz. differences in edaphoclimatic conditions, genetic differences among trees, and the interactions between tree genotypes and the environments in which they grow. If the variations are of genetic origin, it can be manipulated to obtain good gains in some tree characteristics. Early life history characteristics, such as seed traits, are among the most important because they strongly influence patterns of distribution and abundance of populations and species (Rees, 1996; Silvera et al., 2003). Despite stabilizing selection to maintain constant seed morphological characteristics, variability is seen within species, among populations, among individual plants and fruits 
(Jacquemyn et al., 2001; Bañuelos and Obeso, 2003). The variation in seed traits may cause differences in reproductive success, dispersal potential (Yamada and Suzuki, 1999), germination potential (Jacquemyn et al., 2001; Silvera et al., 2003), and seedling establishment (Geritz et al., 1999).

Present study has revealed significant variations between the populations for fruit characteristics of A.malaccensis which can be attributed to the variations in the environmental conditions as well as to the genetic causes (Table 2). The populations considered in this experiment experience a difference in their edaphoclimatic conditions which might have resulted in variations in fruit traits. The results were on par with the works of Sivakumar et al., (2002), who reported that the fruit characters of Teak varied among the different locations. Similar variations in fruit traits between the various provenances has been recorded by the authors Ladipo et al., (1996), Atangana, (2010), Tsobeng et al., (2019) and Uma Shankar \& Idaiarilin (2012). The results are supported by Munthali et al., (2012), who reported significant variations in fruit weight, length and width between different provenances and opined that the variations are due to environmental and genetic causes.

Apart from the fruit characters, A.malaccensis also found to have variations in seed traits of different populations (Table 2). Variability in seed size within species has been reported for many plants by various workers. Several researchers opined that the variations in the seeds mass among the population and within the populations may result from maternal effect, variations in phenology and due to the interaction among the parent plant (Zheng and Sun, 2008). In addition, seed size variation can also result from low or variable selection pressure, resource availability, the effect of position on plants and other physiological factors (Herrera 1990; Stearns 1992). In this study, the climatic variations and topographic factors mainly the altitude, among the populations has its greater contribution. Further, with in the population differences in the local climatic conditions and the soil fertility has a major role to play. Rawat et al., (2006) reported variations in the seed size (seed length, width, test weight and seed volume) among the provenances over the natural range, which was employed as a criterion for the identification of a region in Pinus wallichiana. Similar study was conducted by Hegde et al., (2000) in Acacia auriculiformis and A. mangium, Kumar et al., (2003), Manjare et al., (2003) and Patil et al., (2011) in Pongamia pinnata.

A significant variation in fruit characters among the individual trees was found in the study which indicates a wide genetic base in the population (Table 3). These are the sources and raw materials for the tree improvement programmes which can be exploited. Since the size and weight of the fruits have great implication on the dimension of the seeds they contain which in turn results in their impact on germination makes it a great need to select the populations with higher fruit characters. Uma Shankar and Idiarialin (2012) opined that the tree-to-tree variation in fruit and seed traits is common and may be determined both by genetic and environmental factors. However, it is also argued that the most within-species variation occurs within a plant rather than among plants or populations indicating a greater role of environment during development rather than genetic differences between mothers.

\section{Broad sense heritability of different traits}

The variations can be usefully exploited only when it is known that whether the variations are of genetic origin or are of simply environmental. The heritability values are one 
such tool which separates the origin of variations and indicate how phenotype is affected by environment and genotype. The higher values of $h^{2}$ are indicative of the fact that these phenotypic traits are highly of genetic in origin rather than environmentally controlled. Heritability values for fruit and seed characters tabulated in Table 6 showed higher values which indicates the considerable portion of variance is additive. High additive genetic variance and variation between wild germplasm sources offer good scope for genetic improvement of this species. Such traits which are of genetic origin can be exploited through vegetative propagation or are useful in self pollinating species (Table 5).

\section{Phenotypic and genetic correlations between traits}

Correlations studies done for the fruit and seed traits have shown that fruit width was positively correlated with seed width. Similar positive correlation between pod width with seed width and significant positive correlation of seed width, seed length with 100 seed weight in Pongamia pinnata has been reported by Sahoo et al., (2011). Similar to the findings in the present experiment Okwllo et al., 2018 observed strong uphill positive linear relationships between seed mass and seed number $(\mathrm{R}=0.78)$, total fruit mass and fruit length $(\mathrm{R}=0.73)$, pulp mass and total fruit mass $(\mathrm{R}=0.72)$, and seed mass and total fruit mass $(\mathrm{R}=0.72)$ in Tamarindus indica. The positive correlation between seed length and width has also been reported by Shen et al., (2013). Genotypic correlation of fruit and seed traits with each other have shown higher values than the corresponding phenotypic correlation values indicating presence of higher inherent association between these traits. Sahoo et al., (2011) found higher genotypic correlation than the respective phenotypic correlation in case of pod and seed traits of Pongamia pinnata indicating the presence of strong inherent association between those traits.

In conclusion the existence of variation between the populations and between the trees within the populations is evident with respect to fruit and seed characters of Aquilaria malaccensis. It is important to consider the variation while introducing population from one region to another region.

\section{Acknowledgement}

The authors are thankful to the Indian Council of Forestry Research and Education (ICFRE), Dehra Dun for sponsoring the project and their continuous support in execution of the project.

\section{References}

Atal, C.K. and Kapoor, B.M., 1982. Cultivation and utilization of Aromatic Plants, RRL, CSIR, Jammu-Tawi, India Augustus: 205-206.

Atangana, A.R., 2010. Phenotypic diversity in fruit and seed traits, and neutral genetic diversity in Allanblackia floribunda. $\mathrm{PhD}$ thesis, University of Laval, Quebec.

Bañuelos, M. J. and Obeso, J. R., 2003. Maternal provisioning, sibling rivalry and seed mass variability in the dioecious shrub Rhammusalpinus. Evol. Ecol. 17:19-31.

Chakrabarty, K., A. Kumar and V. Menon, 1994. Trade in Agarwood. In: Barden, A., A.A. Noorainie, T. Mulliken, and M. Song (2000). Heart of the matter: Agarwood use and trade and CITES implementation for Aquilaria malaccensis. TRAFFIC International.

CITES, 1994. Convention on International Trade in Endangered Species of Wild Fauna and Flora. Consideration of proposals for amendment of appendices- 
I and -II Aquilaria spp. and Gyrinops spp.," in Proceedings of the Thirteenth Meeting of the Conference of the Parties. Bangkok.

Falk, D. A. and Holsinger, K. E., 1991. Genetics and Conservation of Rare Plants. Oxford University Press, Oxford. Geritz, S.A.H., vander Meijden, E. and Metz, J.A.J., 1999. Evolutionary dynamics of seed size and seedling competitive ability. Theoretical Population Biology 55: 324-343

Hegde, R., Varghese, M., Padmini, S., Jayaraj, R. S. C., 2000. Variation in seed and seedling characteristics of Acacia mangium Willd and A. auriculiformis A. Cunn. ex Benth. Indian forester, 126(4): 382-388.

Herrera, C.M., 1990. Dissecting factors responsible for individual variation in plant fecundity. Ecology 72:14361448.

Jacquemyn, H., Brys, R. and Hermy, M., 2001. Within and between plant variation in seed number, seed mass and germinability of Primulaelatior: effect of population size. Plant Biology 3, $561-568$

Keller, P. and K. Sidiyasa, 1994.Trees of Balikpapan-Samarinda Area, East Kalimantan, Indonesia. In: Barden, A., A. A. Noorainie, T. Mulliken and M. Song (Eds.), Heart of the matter: Agarwood use and trade and CITES implementation for Aquilaria malaccensis. TRAFFIC International.

Kjaer, E. D., 1997. Sustainable Use of Forest Genetic Resources. The Arboretum/ Danida Forest Seed Centre, Humlebaek.

Kumar, S., Parimallam, R., Arjunan, M.C., Vijayachandran, S.N., 2003. Variation in seed parameters and biochemical composition of Pongamia pinnata (L.)Pierre in Tamil Nadu. In: Proceedings of National Workshop on Jatropha and Other Perennial Oil seed
Species (Eds. N.G. Hegde, J.N. Daniel, S. Dhar), BAIF Development Research Foundation, Pune, India. pp. 103- 106.

Ladipo, D.O., Fondoun J-M. and Ganga N. 1996. Domestication of the bush mango (Irvingia spp.) some exploitable intraspecific variations in west and central Africa, In: Leakey R.R.B., Temu A.B., Melnyk M. and Vantomme, P. (Eds.), Domestication and Commercialization of Non-Timber Forest Products in Agroforestry Systems, Non-Wood Forest Products, No 9, FAO, Rome, Italy, pp. 193-205.

Liu, Y., Chen, H., Yang, Y., Zhang, Z., Wei, J. and Meng, H., 2013. Whole tree agarwood-inducing technique: an efficient novel technique for producing high-quality agarwood in cultivated Aquilaria sinensis trees. Molecules 18: 3086-3106.

Manjare, M.R., Sonawane C.J., Jadhav, N.A., Kunjir, N.T., 2003. Identification of plus trees and genetic variability in karanj (Pongamia pinnata). In: Proceedings of National Workshop on Jatropha and Other Perennial Oil seed Species (Eds. N.G. Hegde, J.N. Daniel, S. Dhar), BAIF Development Research Foundation, Pune, India. pp. 98-99.

Mohamed, R., Jong, P. L. and Kamziah, A. K., 2014. Fungal inoculation induces agarwood in young Aquilaria malaccensis trees in the nursery. J. For. Res. 25: 201-204.

Munthali, C.R.Y., Chirwa. P.W. and Akinnifesi, F.K., 2012. Phenotypic variation in fruit and seed morphology of Adansonia digitata L. (Baobab) in five selected wild populations in Malawi. Agroforestry Systems: 85(2). DOI 10.1007/s10457-012-9500-1.

Ng, L.T., Chang, Y.S. and Kadir, A.A., 1997.A review of Agar (gaharu) producing Aquilaria species. Journal of Tropical Forest Products 2(2): 272 -285. 
Okwllo, J., Okullo, J.B.L., Eilu, G., Nyeko,P. and Obua, J., 2018. Morphological Variations in Tamarindus indica Linn. Fruits and Seed Traits in the Different Agroecological Zones of Uganda. International Journal of Ecology, Vol.18: $\quad 12$ pages; https://doi.org/10.1155/2018/8469156

Patil, V.M.P., Shivanna, H., Surendra, P., Manjunath, G.O., Krishna, A. and Dasar, G.V., 2011. Variability studies for seed and seedling traits in Pongamia pinnata (L.) Pierre. Karnataka J. Agric. Sci. 24(2): 201-203.

Rawat, K., MonikaTyagi and S. Nautiyal and P. Kumar, 2006. Variability Studies of Different Seed Sources of Pinus wallichiana with Special Reference to Seed and Germination Characteristics, The Indian Forester, 132: 373-380.

Rees, M., 1996.Evolutionay ecology of seed dormancy and seed size. Philosophical Transactions of the Royal Society B: Biological Sciences 351: 1299-1308.

Sahoo, D.P., Rout, G.R., Das, S., Aparajita,S, and Mahapatra, A.K., 2011. Genotypic Variability and Correlation Studies in Pod and Seed Characteristics of Pongamia pinnata (L.) Pierre in Orissa, India. International Journal of Forestry Research, Vol. 2011; doi: https://doi.org/10.1155/2011/728985.

Shen, J., Kha, L.A., Kien, N.D. and Pinyopusarerk, K., 2013. Variation in seed traits and oil content in 24 JatrophacurcasL. seed sources from Asia, Africa and Papua New Guinea, Silvae Genetica: 62(6): 257-264.

Silvera, K., Skillman, J. B., and Dalling, J. W., 2003.Seed germination, seedling growth and habitat partitioning in two morphotypes of the tropical pioneer tree Trema micrantha in a seasonal forest in Panama. Journal of Tropical Ecology 19: 27-34.

Sivakumar, V., Parthiban, K. T., Gurudev
Singh, B., Gnanambal, V. S., Aanandalakshmi, R. and Geetha, S. 2002. Variability in drupe characters and their relationship on seed germination in Teak (L.f.). Silvae Genetica 51 (5-6): 232-237.

Stearns, S.C., 1992. The evolution of life histories. Oxford University Press, New York.

Sumadiwangsa, S., 1997. Agarwood as a high-value commodity in East Kalimantan [Kayugaharukomoditielit di Kalimantan Timur]. Duta Rimba 20: 3340.

Tsobeng A., Akem M., Avana M-L., Muchugi A., Degrande A., Tchoundjeu Z., Jamnadass R. and Fabiola, 2019. A Tree-to-tree variation in fruits of three populations of Trichoscypha acuminata (Engl.) in Cameroon, Scientific African 7 (2020): 000235.

Uma Shankar and Idaiarilin L. Synrem, 2012.Variation in morphometric traits of fruits and seeds of Prunus nepaulensis Steud. in Meghalaya, India, Tropical Ecology 53(3): 273-286

Wiriadinata, H., 1995. Gaharu (Aquilaria spp.)PengembangandanPemanfaatan yang Berkelanjutan. Exploitation Workshop Non-Timber Forest Products (Rattan, Agarwood and Medicinal Plants), Forestry Department, Surabaya, 31 July-1 August, 1995.

Yagura, T., Shibayama, N., Ito, M., Kiuchi, F. and Honda, G., 2005. Three novel diepoxytetrahydrochromones from agarwood artificially produced by intentional wounding. Tetrahedron Lett 46: 4395-4398.

Yamada, Y. and Suzuki, E., 1999. Comparative morphology and allometry of winged diaspores among the Asian Sterculiaceae. Journal of Tropical Ecology 15: 619-635.

Zheng, Y. and Sun, W., 2008. Variation in morphophysiological characters of fruits 
of Trigonobalanus doichangensis (Fagaceae) according to individual trees populations and years. Euphytica, 164:
231-238; DOI $10.1007 / \mathrm{s} 10681-008-$ 9716-3.

\section{How to cite this article:}

Ravi, N., R. Hegde, Supriya K. Salimath, Aparna Rajan, S. Shilpa Shenoy and Bordoloi, S. 2020. Variability Studies in Fruits and Seed Characters of Aquilaria malaccensis. Int.J.Curr.Microbiol.App.Sci. 9(11): 2096-2107. doi: https://doi.org/10.20546/ijcmas.2020.911.250 